\title{
Analysis of Ball Lock Separation Mechanism
}

\author{
Ganesh V. Jadhav ${ }^{1}$, Prof. S. B. Wadkar ${ }^{2}$ \\ ${ }^{I}$ (Sinhgad College of Engineering, Pune) \\ ${ }^{2}$ ( Prof. Sinhgad College of Engineering, Pune)
}

\begin{abstract}
The ball lock separation mechanism is used in space vehicles. Various parts of space vehicles have to be separated during flight, to jettison burnt out rocket stages and components that are no longer needed, to uncover equipment, or to deploy payloads.

In this paper the detailed analysis of a 'Ball Lock release mechanism' designed to meet customer specific conditions is presented. Multi-body simulation of mechanism is carried out by using MSC Adams, to assess the displacement, velocity, acceleration, forces and torques acting on released body attached to payload and parent vehicle.

Finite Element analysis is employed to assess the contact stresses between Ball and rings in the most heavily loaded zone, which gives the contact deformation and Stress contours.
\end{abstract}

Keywords-Ball Lock Separation System (BLSS), Finite Element Analysis (FEA), Fore end ring (FR), Retainer Ring (RR), Aft end ring (AR).

\section{Introduction}

The ball lock separation mechanism is used in space vehicles for stage separation. Space vehicle includes artificial satellite and spacecraft having multistage rockets as their carriers. Parts of such space vehicle must be separated during flight to jettison stages and components that are no longer needed, to uncover equipment, or to deploy payloads. For a mission to be successful, the separations must occur at the correct times of flight and with minimum changes in the desired attitudes and rotational rates. There must be no impact between the separating bodies, no detrimental shock loads induced in the structure, and no excessive or harmful debris.

Basically micro-satellite separation system based on 'Ball Lock' release mechanism developed by ISRO for deploying microsatellite up to $150 \mathrm{~kg}$ mass has been successfully used in PLSV. [6] It functions by releasing a preloaded ball locked joint between two rings by rotating a ball retainer ring using pyro assisted thrusters.

Ball lock separation system is designed to separate out the nose cone fairing from payload module system. The ball lock system is basically works on a tongue and groove joint principle. The system can be actuated by hydraulically or pneumatically prior to pyro assembly as an acceptance test. The system characterized by good joint stiffness, light weight construction, tunable jettisoning velocity.[1]

\section{Literature Review}

Separation mechanisms have been used since the space effort began. Until the mid-1960s, many different design concepts were used. However, in recent years there has been a trend toward using a few, wellestablished concepts, and the separation-mechanism components have become more refined. Since the established designs are usually adequate, there has been little interest in developing new concepts. The most of the related work were done in NASA and ISRO. Most of the information on separation mechanisms is contained in internal company documents which receive little if any general distribution; there is not much material on the subject in the available literature.

The paper published by Dr. M. K. Abdul Majeed [1] on the separation and staging mechanisms for Indian SVL-3 launch vehicle was described. This paper describes a unique separation and jettison system for the ascent fairing and a staging system for the apogee motor of the first India satellite launch vehicle.

The technical report used in National Aeronautics and Space Administration published by H. D. Mitchell, NASA SP-8056 October 1970 [2], which describes the space vehicle design criteria and recondition practices (structural).

The research published by Brady Walker [3], on the tribological differences between ball bearings manufactured with steel vs ceramic balls. Though the topic of ball bearing design is mature in the bearing industry, new materials have been presenting themselves as viable options. 
The paper published by Mireia Olave [4] on a procedure for obtaining the load distribution in four contact point slewing bearing considering the effect of the structure's elasticity.

\section{Research Methodology}

The ball lock separation mechanism is designed by considering the two basic criteria first one is it should withstand the structural loads for the given static and dynamic conditions without excessive deformation and mechanism should be dynamically functional. Separation mechanisms shall also be designed to separate structural segments only on command, without re-contact of the segments, and without causing damage or contamination, and without imparting excessive position errors to the continuing segment. Separation mechanisms shall be designed for reliability of performance proportionate with the specified overall system reliability of the vehicle.

Hertz's contact theory and standard empirical formulas were used while designing the component of ball lock separation system.

\subsection{Mechanism Description and Working Principle}

The system consist of upper and lower stage adapter ring held together held together by steel balls which is in turns are held by a retainer ring. The retainer ring is provided with escape tapered hole for the balls. In locked condition, the holes in retainer ring have given an angular offset. During release, the retainer ring is rotated by three pyro thrusters (two for redundancy), nullifying the off-set. Helical compression springs positioned between the flanges impart the required differential velocity.

The three dimensional model of new designed system is created by using Pro/e as shown in Fig.1. The system consists of three rings. The fore end ring attached to satellite payload, while the aft end ring attached with main parent vehicle that is launch vehicle deck.

For releasing the system, the retainer ring is to be rotated overcoming the redial pre-load and friction and shearing the pins through a fixed angle. The system unlocked by rotating the retainer ring in the reverse direction by using hydraulic pushes or pneumatic pushes. The required angle is reaches before the lug of the retainer ring makes contact with the stopper bracket which is mounted on the aft ring.

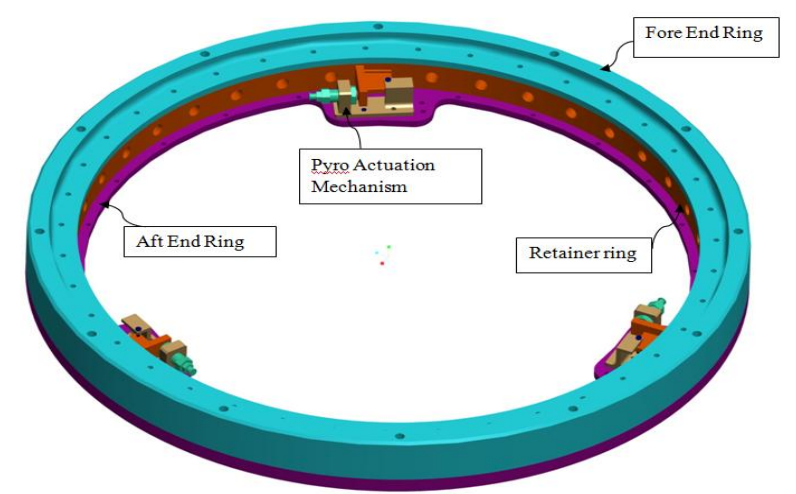

.Fig. 1 3D-model of Ball Lock Separation System before separation.

The detailed top cross-sectional isometric view of one pyro assembly, balls, retainer ring, fore end ring and an aft ring as shown in Fig. 2 The figure elaborates the detailed functional arrangement of ball lock separation mechanism at locked position.

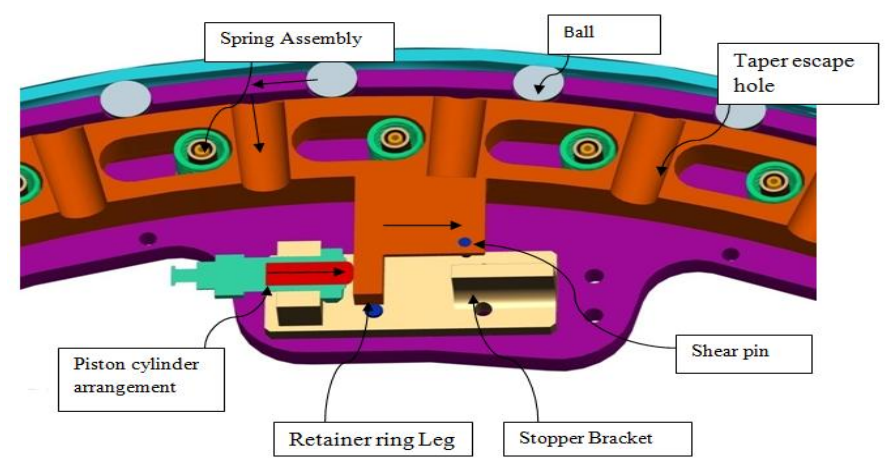

Fig. 2 The mid-plane top cross sectional view mechanism assembly 


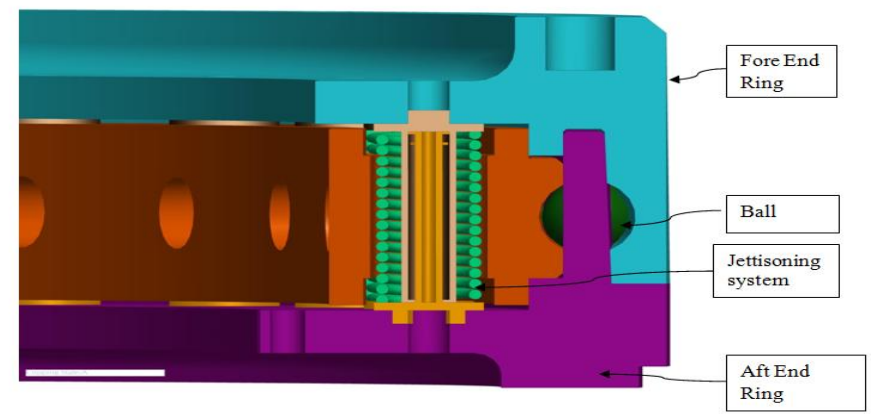

Fig 3 Front cross section view of Ball Lock Separation System.

There are sets of compressed springs providing jettisoning energy for the spacecraft. The springs react on the fore end ring, which front cross section view of BLSS joint. The jettison systems initially in compressed condition are arranged circumferentially. When ball escapes in retainer ring hole, the strain energy of springs is transferred to fore end ring and joint get separated.

\subsection{Solid Modeling of Ball Lock Separation Mechanism}

The solid modeling is technique to prepare to virtual prototype of the actual system. CAD modeling is used by many designers to create elaborate computerized models of object before they are physically produced. For simulation, the finite element model is necessary and for obtaining the finite element model the CAD model is required, and in solid modeling technique it is possible to get cad files so solid modeling is the first step of analysis. Pro/Engineer tool is used for 3D modeling. The mass and volume calculations are obtained from the same tool. For generating the bill of material there is one feature is available in assembly tool bar from that one can get bill of material of mechanism. Solid model of the system and its detail view are shown in Fig.1, Fig.2 and Fig. 3.

\section{CAE Analysis of Ball Lock Separation Mechanism}

Computer Aided Engineering (CAE) is a technique to solve engineering problem by using computer software or program. Software tools that have developed to support these activities are considered CAE tools. In this paper presents the structural as well as motion analysis of the mechanism is done by CAE technique.

The structural analysis of Ball Lock Separation Mechanism is required necessarily for the critical components in the assembly. The critical components are balls and raceways, since all load transfer through ball only. The motion analysis is required for to find the all types movements of mechanism components like balls, retainer ring, fore end ring, aft end ring etc to check its workability in actual operation.

\subsection{Structural Analysis of Ball Lock Separation Mechanism}

Ball lock separation mechanism is approximated to a "Four-Point Angular Contact Ball Bearing" subjected to Bending moment, axial force and lateral force. Four-point angular contact bearing is special case of antifriction bearing, which can take care of axial load, radial load and bending load simultaneously through four points of contacts (two for outer race \& two for inner race), thus transferring the load from inner race to the outer race or vice versa. The material used for the all the rings was aluminum alloy and for the ball chrome steel. The Ball Lock Separation Mechanism is the space application, therefore design of such mechanism is very crucial, so it is designed for worst condition i.e. all loads applied at a time. For the analysis of such condition the one ball sector of mechanism is made. All boundary conditions are applied for most loaded ball.

- Model file name: BLSS_Sector

- FEM Model :BLSS_Sector_Solid_Mesh

- State : Fully defined

- Contact type: Solid to solid

- Number of Elements : 49814

The finite element model of one ball sector and boundary conditions applied to that sector is as shown in Fig. 4 and Fig. 5 


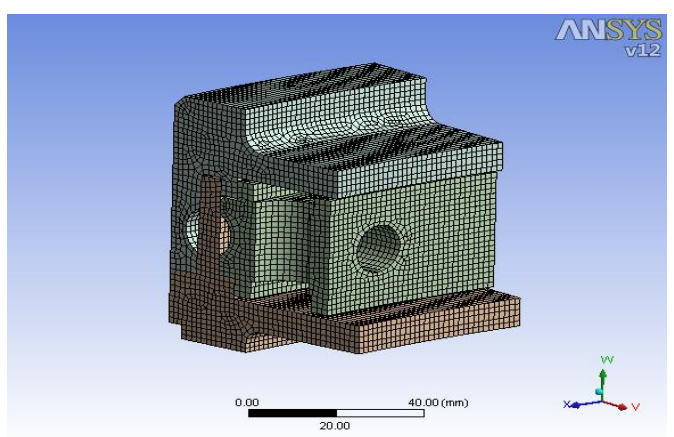

Fig. 4 Finite Element model

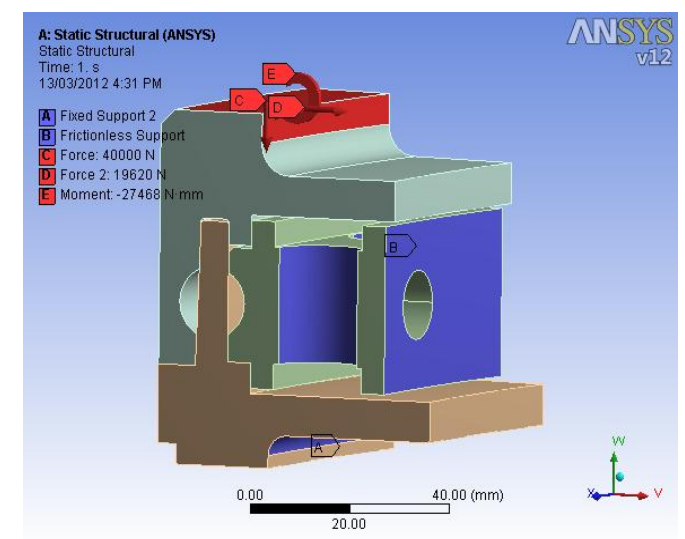

Fig.5 Combined load case and boundary conditions.

The meshing type used for fore end ring, aft end ring and retainer ring is hex dominated and for the ball second order tetra used. The boundary constraint applied according to given loading conditions.

Results and Discussion:

The Fig.6 and Fig. 7 shows that the equivalent Von-Mises stress and total deformation of sector for combined loading.

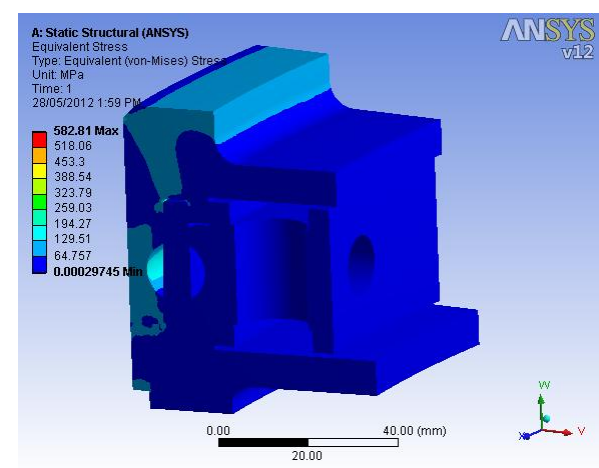

Fig. 6 Equivalent Von-Mises stress

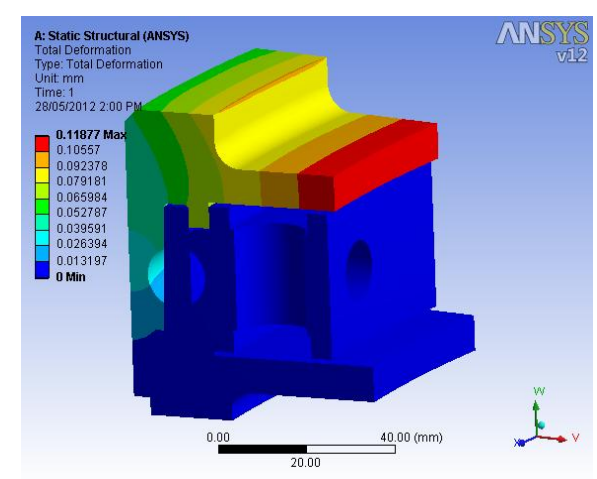

Fig. 7 Total deformation of sector for combined load case. 
Fig. 8 and Fig. 9 show that equivalent Von-Mises Stress contour of ball and fore ring interface and Aft Ring respectively.

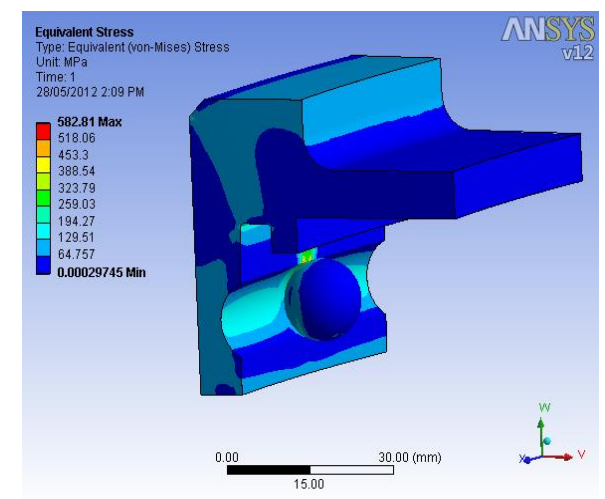

Fig. 8 Equivalent Von-Mises stress contour for Fore end ring

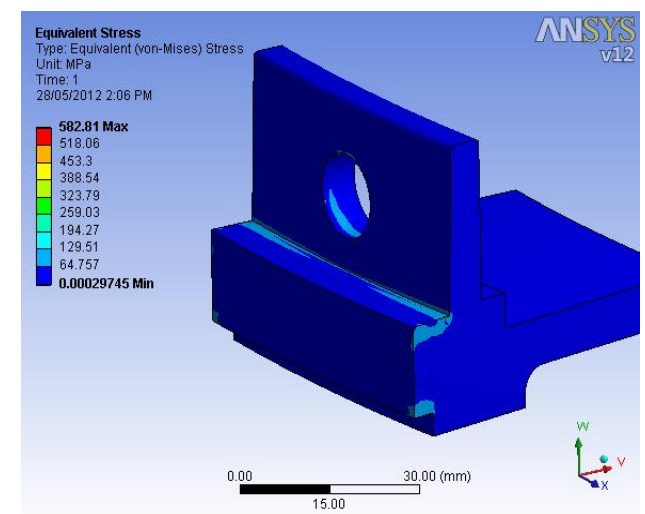

Fig. 9 Equivalent Von-Mises stress contour for Aft Ring.

From above stress contour the maximum stress developed at contact locations and corner or edge of rings. The maximum Von-Mises stress value for the combined loading is $528.81 \mathrm{~N} / \mathrm{mm}^{2}$. Due to high Stresses, it is recommended that a hardening process be incorporated on the contact region.

\subsection{Motion Analysis of Ball Lock Separation Mechanisms}

The motion analysis of Ball lock Separation Mechanism is most important, since this analysis gives the performance parameters like displacement, velocity, acceleration, force and torque etc. at time of separation. For mission to be successful the separation must occur at correct times of flight. The motion analysis was carried out for whole mechanism assembly. The commercial package MSC Adams MotionView 2010 is used for this analysis.

Procedure: Mass properties are defined creating new material model which includes Young's modulus, Poisson's ratio and density of material. The software integrally calculates the mass and moment of inertia of the component. The constraints are defined to get predicted motions of parts. The contacts were defined between balls and three rings. Revolute joint was given to retainer ring at the center. Aft ring fixed at marker location. Cylindrical joints were used for pyro-actuator piston cylinder arrangement.

By verifying the mechanism simulated for 20 milliseconds. The radial force on the ball which are coming from the fore end ring must be deactivated when the ball escape in the tapered hole. Script was written by using simulation script of type Adams/Solver Commands. The script required Adams solver id which is got from info command. Also for pryo actuator mechanism the piston is of type impact, and there also deactivation of piston for after striking retainer ring to the stopper bracket.

By iterative trial and error method the approximate time required to escape the ball in tapered hole and time required for impact the retainer ring on the stopper bracket was calculated. This calculated time used for writing the script for final simulation.

The Fig. 10 shows that Adams model before simulation with all material properties and constraints defined. 


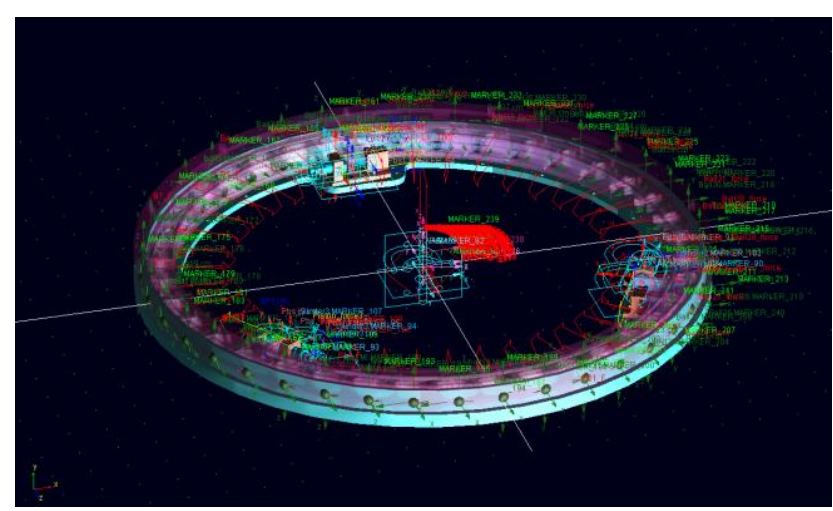

Fig. 10 Adams model before Simulation

The equivalent spring force is applied to the marker of the fore end ring. Fig. 11 shows that the clean separation of Fore end ring of mechanism.

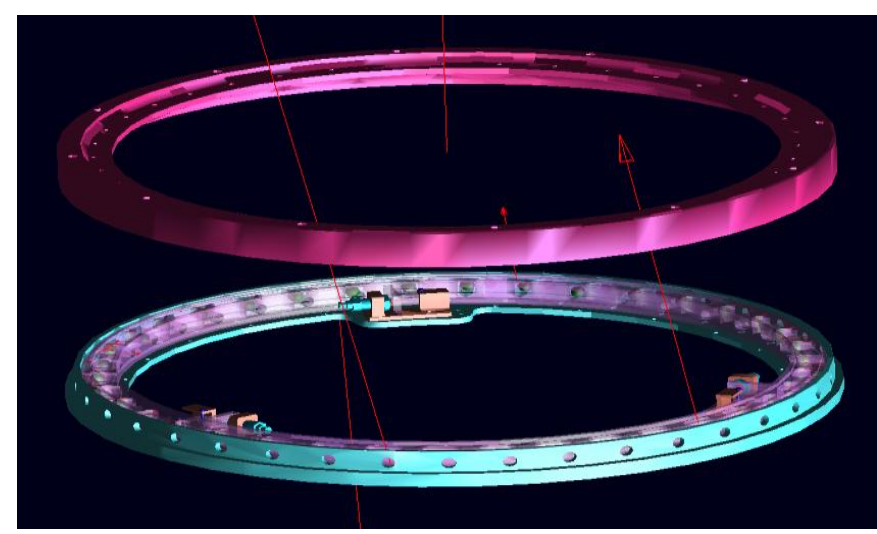

Fig. 11 Clean separation of Fore End Ring from the Mechanism.

By using Adams/PostProcessor MD Adams 2010 the results were plotted for different performance parameters with respect to time. The simulation solve was given for 20 milliseconds. Fig. 12, shows that the separation of fore end ring i.e. the velocity of fore end ring vs time for single actuator works at a time.

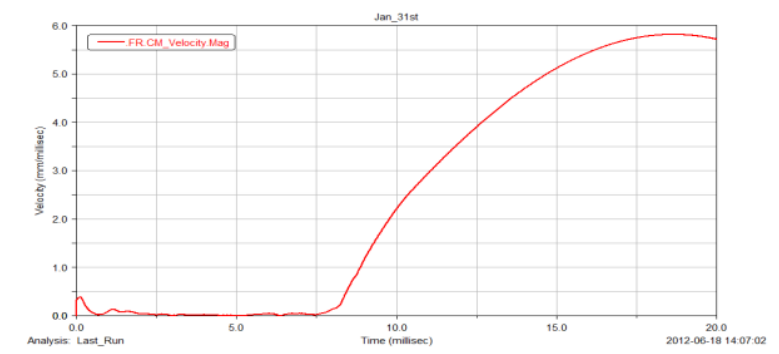

Fig. 12 Velocity of fore end ring with respect to time (Single Actuator)

From the graph the separation time and time required to achieve $2 \mathrm{~m} / \mathrm{s}$ jettison velocity is tabulated as in Table 1

Table 1 Separation start time $\&$ time req. to achieve $2 \mathrm{~m} / \mathrm{s}$ jettison velocity.

\begin{tabular}{|l|c|c|}
\hline \multicolumn{1}{|c|}{ Number of actuators } & Separation time(millisecond) & $\begin{array}{l}\text { Time required to achieve jettison } \\
\text { velocity(millisecond) }\end{array}$ \\
\hline One & 7.707 & 9.775 \\
\hline Two & 6.474 & 8.263 \\
\hline Three & 4.511 & 6.285 \\
\hline
\end{tabular}

The acceleration graph shows, spring force acting continuously on fore ring as it is in compression state. Fig. 13 shows acceleration with respect to time graph of FR for third case. 


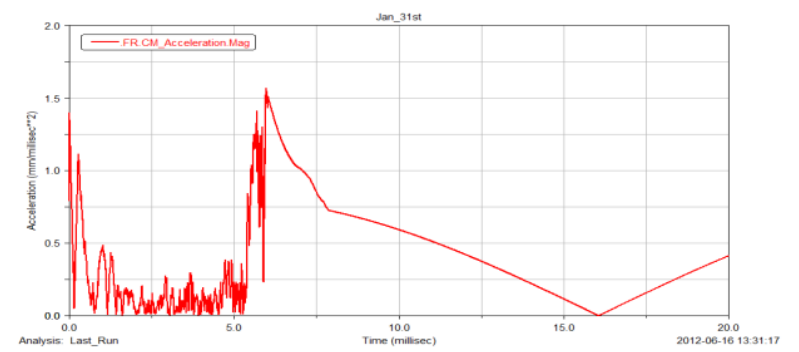

Fig. 13 Acceleration with respect to time of Fore End Ring

The troughs and crest is due to instability of the fore end ring before separation since pay load and spring force acting on it. After separation the velocity linearly increases therefore acceleration of fore end ring linearly decrease. The displacement of fore end ring form CG position with respect to time is shown in Fig. 14

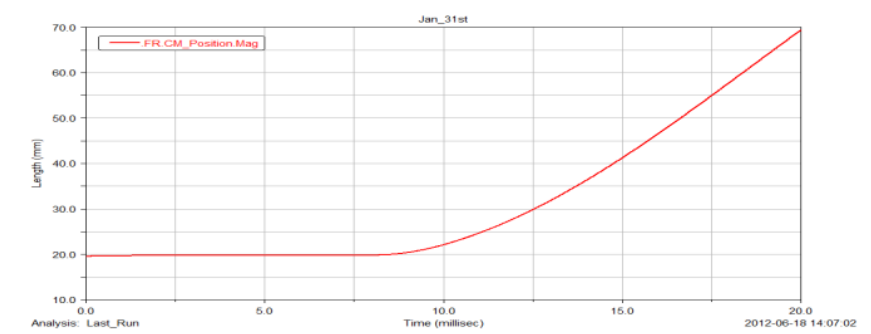

Fig. 14 The displacement of fore end ring form CG with respect to time.

From above graph it is seen that within 20 milliseconds distance travelled by FR is about $70 \mathrm{~mm}$.

\section{Conclusion}

1. The paper attempted to cover the expanse from conceptual design to practical design with the help of Computer Aided Engineering technique.

2. Most of the time Space vehicle missions failed at separation stage because of lack of kinematic data of separating mechanism. Multi-body dynamic simulation gave the approximate behavior i.e. kinematic and dynamic data of separating components.

3. Multi-body simulation by MSC Adams software visualizes event of separation in virtual environment. This helped in evaluating performance of Ball Lock Separation Mechanism.

4. Explicit dynamic analysis can be performed with help of MSC Adams results for more precise strength evaluation of mechanism.

5. Scope can be further extended to check the vibrational behavior of whole assembly by using modal analysis.

6. Experimental testing for reliability and performance of the Ball Lock Separation Mechanism under various environments needs to be carried out and to correlate with analytical and simulation results.

\section{Acknowledgement}

The authors gratefully acknowledge the continual support and precious technical suggestions provided by Dr. Y. P. Reddy of Sinhgad College of Engineering, Pune and principal guide Mrs. V. R. Ramaswamy, Director, Aprameya Associates, Pune.

\section{References}

[1] M. K. Abdul Majeed, K. Natarajan, and V. K. Krishnan Kutty, Separation and Staging Mechanisms for Indian SVL-3 Launch Vehicle, Special Report from Vikram Sarabhai Space Centre, Indian Space Research Organization, Trivandrum, India, 1984, Pp.277-299.

[2] D. H. Mitchell, Flight Separation Mechanism, National Aeronautics and Space Administration, NASA SP 8056, Oct 1970,Pp.1-35.

[3] Bernurd J. Humrock und Wdlium J. Anderson, Arched Outer Race Ball Bearings", National Aeronautics and Space Administration, NASA TN D 6765, April 1972, Pp.1-32.

[4] Brady Walker, "Project: Comparison of a Ball bearing with Steel balls versus Ceramic balls", Journal of Friction and Wear, 2007, Pp.1-24.

[5] B. Laxmi Narayana, H.N. Suresha Kumar, B.S.Natraju, Accordion deployment simulation of solar array using ADAMS, $3^{\text {rd }}$ National Seminar and Exhibition on Aerospace and Related Mechanism, Hyderabad, India, Asia 1999,Pp. 0-5.

[6] S. Somanath, V. K. Krishnan Kutty, E. J. Francis, Dynamics Simulation of pyro actuated 'Ball lock' separation system for micro-satellites to evaluate release shock, Aerospace Mechanism Publications, 2006, Pp.1-8. 